\title{
Closing the Gap in State Legislative Races: The Effect of Campaign Spending on Ballot Drop-off
}

\author{
Matthew Davis ${ }^{1} \&$ Priscilla Southwell ${ }^{2}$ \\ ${ }^{1}$ League of Conservation Voters Education Fund, Washington D.C., USA \\ ${ }^{2}$ Department of Political Science, University of Oregon, USA \\ Correspondence: Priscilla Southwell, Department of Political Science, Eugene, OR 97403, USA. E-mail: \\ psouth@uoregon.edu
}

Received: April 19, 2015 Accepted: May 12, 2015 Online Published: May 27, 2015

doi:10.5539/jpl.v8n2p118 URL: http://dx.doi.org/10.5539/jpl.v8n2p118

\begin{abstract}
This article analyzes ballot drop-off in state legislative elections. Publicly available campaign finance information and election turnout results from the State of Oregon from 2008-2014 were used to test the collective and individual effects of various campaign expenditures on ballot drop-off. The results show that overall campaign expenditures have a statistically significant effect on reducing ballot drop-off. However, the effects of specific types of expenditures vary; media and professional expenditures help to reduce ballot drop-off, but field and general office expenditures have little effect.
\end{abstract}

Keywords: drop-off, state legislative elections, turnout, undervote

\section{Introduction}

All political campaigns face the daunting task of deciding how to best allocate their limited resources to improve their chances of victory. These decisions involve a calculated financial investment in a range of communication techniques to persuade voters and turn them out to vote. State legislative races, which are inevitably less salient, usually account for relatively lower turnout compared to the races at the top of the ticket. The phenomenon of lower turnout for races further down the ballot (i.e. state legislative seats, municipal elections and ballot measures) from those at the top of the ballot (presidential, congressional and gubernatorial) is often referred to as ballot "drop-off." Each one of those voters who fails to fill out their complete ballot is a missed opportunity for a legislative vote. This article is an analysis of the effectiveness of various communication strategies and campaign expenditures used in certain state legislative races to offset this ballot drop-off, by analyzing data in Oregon in 2008-2014.

In each of these election years, all state legislative races in Oregon had lower voter turnout in their district than the top of the ticket, as expected. Campaign practitioners tend to think this effect is caused by an information gap between the top of the ticket, where money spent and media coverage is greater, and the "down ticket" races. In addition, such campaign advisors see these drop-off voters as their best chance to increase relative turnout, because the person has already been convinced to turn in their ballot. In a Downsian sense, they have already invested the time and effort to vote, so the marginal costs of voting in these lesser contests should be more easily overcome. To win, legislative candidates must account for drop-off and build a strategy to close the turnout gap. This research seeks to advance knowledge of campaign spending and examine the assumption that increased spending in state legislative races decreases ballot drop-off. In addition, it will take a look at individual expenditure types to weight the value of one approach over another.

During the 2012 election cycle in Oregon, competitive legislative races consistently saw combined spending above $\$ 1$ million (ORESTAR). This reflects the competitive nature of these races as political parties grapple over control of the legislative branch. In Oregon, limits on campaign expenditures have taken a back seat to transparency, leading to legislative races that are among the most expensive in the nation. Consultants and staff often have a background in larger campaigns, so local races often become a scaled-down version of those efforts. However, are there are no guarantees with the same types of campaign expenditures work as well with lesser races.

\section{Previous Research}

The paucity of research on this topic at the state legislative level often relate to a lack of reliable data available in 
smaller districts, as well as the widely varied organizational structure of legislative bodies from state to state. A part of this problem was remedied in 1987 by the Inter-university Consortium for Political Science Research (ISPSR) with the creation of a database with state legislative election results from 1968 to 1986 (Carey et al., 2000). However, barriers to analysis at this level continue to be considered "severe" by researchers (Austin et al., 1991). In addition, turnout in state legislative elections is not seen as a significant variable in analyzing races at other levels.

Voter participation rates have been a main focus of research around American politics for decades. Across the United States, turnout in elections is low compared to other western democracies. This lack of participation creates questions about of the legitimacy of government. Historical election results have shown consistently that turnout rates are even worse at the state and local level (Oregon Elections Division). New trends in controlled experiments have led to more precise measurements of the turnout effect of various campaign activities (Green $\&$ Gerber, 2000). More specifically, research has shifted towards analyzing the most effective medium of communication to increase turnout. However, some of these efforts remain private as practitioners jockey to gain a competitive edge in high stake elections.

Existing research has shown that money impacts campaign outcomes and contributes to voter participation. This effect has been proven highly significant at the state legislative level (Hogan 2013). However, long before this published research, the assertion that money affects outcomes had become an axiom in campaigns. Money is a finite resource, so practitioners are more interested in what specific types of expenditures are likely to increase vote share and turnout. There is a gap in the literature when it comes to the effects of individual types of expenditures, as compared to others. This could be due in part to the difficulty in obtaining data on the breakdown of specific expenditures within a campaign. Campaigns do not usually share information on strategies unless required to do so, as this experience is usually shared within political parties or organizations in the hope of a better outcome in the future. In Oregon, candidates are forced to report detailed information on expenditures to the Secretary of State, making such analysis possible.

Empirical research and controlled experiments have shed light on the turnout effects of individual campaign actions. Direct voter contact - also known as "field" - efforts by campaigns have proven to be a relatively inexpensive, but important, way for local campaigns to persuade and turn out voters (Green \& Gerber, 2008). Face-to-face contact at the doorstep has been shown to increase turnout by nearly ten percent. In addition, phone calls have a smaller, but statistically significant effect (Gerber \& Green, 2000). Campaigns across the country have adapted more "grassroots" activities into local campaign activities and expenditures. An added benefit of such direct voter contact is that it often contains an element of volunteerism, which is free outside of management costs. Many local races rely on volunteers who donate time for free to walk various neighborhoods.

More traditional forms of voter communication like direct mail, in general, may affect turnout by around 1 percent (Green \& Gerber, 2003), but others have concluded that the effect of mail may have a greater impact on changing the vote share of a candidate among individuals who were already going to cast a vote. Television advertising has been shown to have a mixed effect on turnout. Previous research suggests that television causes a substitution effect away from other forms of media, leaving people less informed and reducing turnout (Gentzkow, 2006). Other results suggest that turnout effects may exist, but in larger media markets a disproportionate level of attention will be paid to higher profile races, drowning out turnout on down ballot races (Althaus \& Trautman, 2006). There is a gap in the literature when it comes to comparing the different effects of these expenditures within a given campaign budget. In actual campaigns, decisions must be made about the relative advantages of one expenditure over another, which will be informed by the effects on turnout and persuasion.

While research on general turnout is helpful to state legislative races, not all turnout is created equal. These studies have begun to form a model for how campaigns can increase voter participation, but considerably less emphasis has been put on applying these results directly to legislative races that constantly receive lower turnout then the top of the ballot. The data collected for this article shows ballot drop-off in all legislative districts.

\section{Analysis of Oregon Data}

By using a data set unique to Oregon, where all individual expenditures made by legislative candidates are reported, analysis of the overall impact of money on drop-off as well as the individual effects of various campaign activities within legislative campaigns can be seen. This can address questions that plague campaign practitioners for any down ballot races: What specific campaign activities contribute to reducing the ballot drop-off from the top of the ticket and proportionally increasing turnout? Answering this question could have profound effects on campaign strategy at the local level. Does direct voter contact really work at the state legislative level, or are other 
methods more effective in getting voters to cast their ballot for lesser races? The concept of coordinating campaigns of various sizes could be advanced, and campaign expenditures patterns could be changed. If spending money on a specific campaign activity to improve turnout is ineffective, perhaps emphasis will be shifted to other types of expenditiures.

\subsection{Ballot Drop-Off and Turnout}

Undervote - which is highly correlated with and often equated with ballot drop-off - is the number of votes that are not cast for a given race on a ballot. In other words, the number of ballots in which the race was left blank. Undervote for the presidential race in Oregon was less than one percent in 2012, while other races suffered greater - but varying - degrees of undervote depending on the office being sought (Oregon Elections Division). If there is not a presidential candidate, similar results exist for whoever is on the top of the ticket. This is consistent throughout historical election results and has led to the widely accepted conclusion that, in general, turnout is driven by the largest, most high profile race on the ballot.

The study of ballot drop-off is focused on what causes individuals to fail to vote down the ticket. Research has shown that there are coattail effects that increase turnout for down ticket races, as turnout increases for the top-of-the-ticket (Hogan, 2005). These effects are particularly pronounced when competitive races are taking place. In general, rates of turnout are higher during presidential election years than mid-term elections. This is due in large part to the high profile nature of these races and the higher rate of participation by less committed voters. Studies have shown that rates of change in turnout for top-of-the-ticket races during non-presidential years, compared to turnout in presidential years, are approximately the same in magnitude for legislative races (Austin et al., 1991). This means that while overall rates of turnout fluctuate, the proportional rates of drop-off between the top of the ticket and legislative races remains consistent. This consistency points to systemic reason for drop-off. But what causes this?

Analysis of ballot drop-off has been most closely studied at the judicial level. Results have indicated that the turnout may have less to do with socioeconomic considerations, and more to do with election characteristics like closeness of the race and the type of election (Johnson \& Younger, 2008). These results are closely related to studies on "low information" elections. As voters move to down ballot races, they face increasing barriers to decision making that can lead them to leaving a race blank. The addition of information as basic as partisan affiliation has shown to be significant in impacting results (Klein \& Baum, 2001).

The phenomenon of ballot roll-off is a bit paradoxical, because of all the barriers that have already been overcome to cast a ballot. Anthony Downs created a model for the calculus of voting that said the reward of voting was equal to the benefits of winning, multiplied by the probability that it is a deciding vote, subtracted from the costs of voting (1957). Seeing this model as overly simplistic, Riker and Ordeshook tweaked it further by adding in the concepts of civic duty and voter satisfaction. When applied to the concept of voter roll-off, this raises a question about the utility (or lack-there-of) of local races (1970). Proximity to voting location, transportation, legal restrictions and other barriers to voting are no longer a factor once the voter is already filling out the ballot. The Downsian model, and later Riker and Ordeshook, suggests that total votes cast can be seen as an aggregate measure of the value of a race, and down ballot races seem to consistently provide a lower level of reward to voters than up-ticket races.

Research points to three main theories of what causes ballot drop-off. The first is a lack of significance or salience that leads a voter to abstain from voting. It is well established that if voters are unsure of candidate names or duties of a given office or feel that an office is insignificant, they are less likely to have strong preferences (Burnham, 1965). This represents the idea of a voter information "gap". During most elections, the greatest amount of money, visibility and attention goes to the races at the top of the ballot, causing down ballot races to be drowned out. Voters are therefore exposed to less discussion about the candidates and the office they seek, leaving them less informed and less likely to identify a purpose in voting for the position.

With each step down the ballot, budgets tend to get smaller, and voter information on the race decreases. The limited exception to this may be a turnout effect that can be found in down-ballot gubernatorial races during years when a presidential race is up the ticket (Boyd, 1986; Hill \& Leighly 1993, 1994). However, these races are statewide, well-funded and heavily covered by the media, making them fundamentally different than legislative races. In 2012, the recall election for the Wisconsin Governor's race topped nearly $\$ 80$ million in campaign spending (CBS, 2012) In these situations, budgets allow candidates to perform like a top-ticket race because they've seemingly bought their way out of the information gap. Legislative races are substantially smaller and receive less media attention. The money raised by these candidates is spent in smaller districts, making comparisons of per capita spending more relevant than aggregate spending, but the difference in spending is still 
significant. Legislative races cannot keep pace and their message struggles to reach voters. Some evidence shows that even highly competitive state legislative races are unlikely to reach voters (Jackson, 1997).

A second explanation is a concept called "voter fatigue". While some researchers use this term interchangeably with the term roll-off, others use it to describe the contributing factors that make a voter "grow tired of the process before completing a long ballot," (Bullock, 1996). For the purposes of this paper, we will be using the latter definition. Some of the contributing factors to fatigue include proximity to a polling place, issues with childcare, long lines to vote, weather, emergencies and more. However in Oregon, many of these barriers are reduced by the vote-by-mail system which could have a positive effect on turnout for down ballot races. As Priscilla Southwell finds, the extra time allowed for decision making can help vote by mail formats work "to facilitate voter participation for ballot measures or other less visible contests,"(2009). While questions still remain about how much this affects voters who are not motivated to vote in the first place, the vote-by-mail system in Oregon makes fatigue in local elections a less cogent argument for why drop-off occurs.

A third explanation for drop-off is confusion at the ballot. This can be caused by something as simple as not realizing there was a second side to a ballot. Previous research by Nicholson showed that lowering a ballot proposition 10 slots on a California ballot increased roll-off by over a percentage point (2007). Bowler Donavan and Happ find that "under preferential systems or where a large number of elective offices and/or propositions are on the ballot, the decisions facing voters are quite complex," (1992).

With the system of vote-by-mail in Oregon, the impact of the information gap and saliency are likely the strongest factors in affecting ballot drop-off for down-ballot races. With the increasingly advance communication and targeting techniques of modern campaigns, campaigns are focusing more on communicating the right messages to the right people in an effort to close this gap. While there is an expectation of strong correlation between the total amount of money spent on campaigns and turnout, the optimal distribution of funds remains unclear.

\section{Data Analysis}

In Oregon, it is possible to obtain data on campaign spending through an online database managed by the Secretary of State called ORESTAR. State laws governing transparency in elections require all candidates, ballot measure campaigns and political action committees to report any expenditure or contribution. The nature of the financial interaction is made publicly available if the value of the transaction exceeds $\$ 100$ during a calendar year. Even if the original transaction is below the limit, once a transaction is performed by the same entity in that calendar year to push the total over $\$ 100$, all transactions are displayed. Any amount below this for a given year, and the amount shows up as a miscellaneous expenditure (or contribution). With the focus of this research on major campaign communication expenditures, nearly all relevant information is above this threshold and publicly available.

The full history of contributions and expenditures can be exported for each campaign committee. Publicly disclosed information includes the payee, recipient, amount, transaction date, and nature of the transaction. The amount of information displayed for each transaction makes it easy to identify the purpose of the expenditure and classify it for the purposes of this research. Nearly 100,000 individual expenditures from 2007 - 2014 were categorized, based on their descriptions, into the variables of interest described below.

The Oregon Secretary of State's website provided data collected on registration and historical election results. Total presidential turnout by state legislative district was not readily available, so the precinct level information was obtained directly from the secretary of state's office and summed by district.

\subsection{Methodology}

Two multivariate regressions were conducted on data from the 2008 - 2014 election cycles in Oregon. Candidates begin spending money during the year preceding the election to maintain or establish name recognition and traditionally spend a few weeks following the election to pay off campaign debts that were incurred prior to the Election Day. Therefore, all expenditures made during the period between January $1^{\text {st }}$ of the year preceding the election, through December 31 of the election year, are included in the expenditure total for that election cycle. This is done for each election cycle.

Consistent with the focus of this research, the endogenous variable will be undervote in both regressions, which will be used as a very close proxy for drop-off. Total votes cast for the top ticket race is not always available by legislative district, necessitating the use of undervote. In the first regression, we analyze the impact of total expenditures on ballot drop-off, while controlling for factors that have been proven to affect overall turnout in previous research. Money has been shown to increase turnout in state legislative races (Hogan, 2005), but its 
effects have not been applied directly to ballot drop-off, making the first regression an important step in establishing correlation between money and the magnitude of drop-off. Total expenditure was expected to have a negative sign on its coefficient because it would reduce drop-off.

The original equation for the regression is as follows:

$$
\begin{gathered}
\text { Undervote }_{i t}=C_{i}+C_{t}+B_{1} \text { Registration }_{i t}+B_{2} \text { Incumbent }_{i t}+B_{3} \text { Third Party }_{i t}+B_{4} \text { Total Expenditure }_{i t}+ \\
B_{5} \text { Unopposed }_{i t}+e
\end{gathered}
$$

In the second regression, we explain the advantages of individual expenditures by showing their impact on drop-off, while also controlling for the 2012 presidential election year.

\subsection{Dependent Variable}

The UNDERVOTE variable represents the difference in $(i)$ district during $(t)$ election year between total ballots cast in each district and those cast for state representative. That amount will be divided by the total number of registered voters to make it proportional to the size of each individual legislative district, where registration can vary. In 2012, where data is available on presidential turnout at the legislative level, it is clear that undervote and drop-off are nearly identical, reinforcing the use of undervote as a proxy.

\subsection{Explanatory Variables}

\subsubsection{Intercepts and Error}

The term $\left(C_{i}\right)$ represents the intercept of factors specific to each district, but common to all election cycles. The term $\left(C_{t}\right)$ represents the intercept of factors specific to each election cycle, but common to all districts. The term $(e)$ represents the residual error.

\subsubsection{Expenditure Variables Overview}

The data on campaign spending obtained from ORESTAR will be separated into six categories: BROADCAST, LITERATURE, FIELD, PROFESSTIONAL, GENREAL OPERATING ad OTHER ADVERTISING. These expenses comprise the major components of a modern campaign and align with categories defined in ORESTAR filings. In addition, total expenditure was calculated from all available expenditure data. We know from previous research that total campaign spending is significant in increasing overall turnout, but this has not been applied directly to drop-off. The categorized expenditures will allow us to see if any type of campaign spending has more impact than another.

Total campaign expenditures were summed for all candidates in the district who reported in ORESTAR and are represented in the variable TOTAL EXPENDITURES. Since drop-off is hypothesized to be directly impacted by the information gap, the assumption is that all campaign activity in a given district will contribute to raising the profile of the race. Therefore, it will not matter which candidate spent the money, so there is no separation of expenditures by candidates, or variable related to party affiliation.

Expenditure descriptions and categories were written by the campaigns themselves and verified by the secretary of state, which led to some small inconsistencies across districts. However, each expenditure lists a filing category, expanded description and recipient which allowed for each of the nearly 100,000 observations to be grouped into categories.

\subsubsection{Expenditure Variables Description}

The BROADCAST variable includes anything related to the production of TV advertisements or the purchase of airtime. This variable includes radio advertising as well, because ORESTAR classifies those expenses together. LITERATURE includes all expenses related to printing, production and postage for direct mail, stock cards or flyers. FIELD captures any expenses that were related to direct voter contact activities like knocking on doors, calling voters over the phone or emailing. This excluded expenses related to monthly phone service, which was seen as an office expense. OTHER ADVERTISING is a catch-all category that captured expenditures on promoting the candidate that didn't fall into other categories. These included expenses like lawn signs, billboards, newspaper advertising, weeklies and more. GENERAL OPERATING includes all expenses related to running an office, utilities, supplies and rent.

The final, and perhaps most complicated, expenditure variable was PROFESSIONAL expenses. Extensive research has gone into testing the significance of professionalism within legislatures. However, researchers struggle with how to measure the component parts that make up professionalism (Carey et al., 2000). In addition, analysis of professionalism is most often used when looking at cross-sectional data across states, and is directed at the professionalism of the chamber itself. Looking at the level of professionalism within individual campaigns is 
even less easily quantified.

In this study, the goal was to capture money spent on staff, consulting, and polling which each make a campaign more professional and sophisticated. Research has shown that professionalism in the legislature can impact campaigns (Abbe and Herrnson, 2003). Staff and consulting generally give candidates a significant advantage over those who don't have them, assuming the advice and work is productive. The challenge in this variable is that staff and consultants were sometimes coded as specific expenses that find their way into other categories. Examples include ads that are designed by consultants or volunteers who are recruited by staff to contribute to field efforts. Sometimes these efforts were expensed along with other costs and other times they were singled out and billed separately. We would expect this to cause correlation with the other variables in the model.

\subsubsection{Control Variables}

To account for the impact of district size, we controlled for the total voter registration in the district. This is accounted for in the dependent variable by making drop-off a percentage of total turnout in the district. However, district size is likely to impact the right-hand-side variables too by affecting the amount of money spent to reach the amount of voters needed to win. Some districts are much larger and therefore they have larger target universes for activities like voter outreach and direct mail. For some variables like television, this might be irrelevant because media markets do not follow district boundaries, but for other it may affect the amount spent on certain activities.

Another factor in legislative voter turnout is the competitiveness of a given district. This is widely acknowledged as a predictor of things like media coverage and ultimately, money spent. Factors that relate to a district being competitive include the demographic makeup of the district and the registration advantages of a given party. These tend to remain approximately the same over time, allowing for past district results to be a great predictor of future competitiveness. The variable in this model is a dummy variable with a value of one if the race was decided by less than $10 \%$ of the final vote share in one of the last two cycles, and zero if it was not. Since investment can vary based on a variety of factors in any given cycle, the previous two cycles were used to capture a more accurate assessment of whether a district is potentially competitive.

A significant amount of literature has been published on the advantages of incumbency. It has been widely agreed that incumbents have higher rates of re-election (Uppal 2008; Troustine, 2009). There is less agreement about exactly why. Some argue that incumbency ties into the idea of professionalism, and that incumbents are more likely to understand how to strategically use resources to win (Troustine, 2009). Others argue that there are a multitude of mitigating factors like district size, term length and electoral formula that significantly impact the value of incumbency (Carey et al., 2000). This research tends to focus on margin of victory, rather than on direct turnout effects of incumbency. One could argue that the true impact of incumbency is on how competitive a race may be, which would ultimately impact drop-off rates.

\section{Multivariate Results}

As shown in Table 1 below, TOTAL EXPENDITURES and UNOPPOSED are statistically significant. Spending is negatively correlated with undervote, while being in an unopposed race is positively correlated. In unopposed races, little money is spent, so state legislative candidates rarely attract attention. We can see that the R-squared is quite high, which shows that money and the presence of an incumbent explain most of the undervote.

Table 1. Regression analysis of ballot drop-off in state legislative races in Oregon, 2008-14

\begin{tabular}{|c|c|c|c|}
\hline Independent Variables & Coefficient & Standard Error & $\mathrm{T}$ \\
\hline Constant & 0.152 & 0.061 & 2.50 \\
\hline Registration (Thousands) & $-1.00 \mathrm{E}-05$ & $1.53 \mathrm{E}-06$ & -0.65 \\
\hline Incumbent in Race & -0.001 & .001 & -0.14 \\
\hline Unopposed & 0.174 & 0.008 & 21.63 \\
\hline Third Party in Race & -0.009 & 0.008 & -1.11 \\
\hline Total Expenditure (Thousands) & $-6.00 \mathrm{E}-08$ & $2.02 \mathrm{E}-08$ & -2.97 \\
\hline$N=240$ & & & \\
\hline
\end{tabular}

In Table 2, each category of expenditures was converted into a percentage of total spending. This shows us 
which types of spending -- regardless of overall spending, district size or other factors - have a significant impact on undervote. Broadcast, literature, other advertising and field spending are types of expenses that are significant and negatively correlated with undervote: Increasing the amount spent on these activities, relative to overall spending, reduces undervote. In addition, these types of expenditures are consistent with expensive campaigns. Races that spend in these areas are usually spending large amounts overall, so these individual expenditures are also correlated closely with overall spending levels. Conversely, campaigns that spend a higher percentage of their total spending on things such as general operating expenditures or volunteer activities like field may have a smaller budget and be less visible. In this table we also controlled for the election context, by including a control for the 2008 and 2012 presidential election, when we would expect a higher degree of ballot drop-off. This proved true, as the presidential dummy variable is significant and positively correlated.

Table 2. Regression analysis of ballot drop-off across expenditure type, state legislative races in Oregon, 2008-14

\begin{tabular}{lrrr}
\hline Independent Variables & Coefficient & Standard Error & $\mathrm{T}$ \\
\hline Constant & -1.62 & .630 & -2.57 \\
Registration (log) & 0.165 & 0.060 & 2.76 \\
Incumbent in Race & -0.027 & 0.009 & -2.94 \\
Unopposed & 0.184 & 0.009 & 20.2 \\
Third Party in Race & -0.003 & 0.010 & -0.30 \\
General Operating & -.003 & .038 & -.09 \\
Field & -.078 & .109 & -.71 \\
Broadcast & -.114 & .035 & -3.25 \\
Professional & -.094 & .025 & -3.70 \\
Other Advertising & -.141 & .056 & -2.50 \\
Literature & -.079 & .027 & -2.87 \\
Presidential Dummy & .041 & .006 & 7.14 \\
\hline $\mathrm{N}=240$ & & & \\
\hline
\end{tabular}

\section{Conclusion}

In essence, we have found that most campaign expenditures at the state legislative levels do help to offset the tendency of voters to ignore lower-level contests. A higher level of overall campaign spending does help to reduce ballot drop-off. However, the effectiveness of each type of expenditure varies. Specifically field expenditures and general operating costs are the least effective in reducing ballot drop-off. These findings thus provide a refinement of the earlier works of Gerber and Green (2008) and Green and Gerber (2000). Direct voter contact can be effective in increasing overall voter turnout; however; our findings suggest that other mechanisms work better in getting voters to cast their ballot for lesser races, once they have decided to vote. Clearly, state legislative campaigns need to raise funds and spend them effectively, and these findings suggest that certain activities are more effective than others in reducing ballot drop-off.

\section{References}

Abbe, O. G., \& Herrnson, P. S. (2003.) Campaign professionalism in state legislative elections. State Politics \& Policy Quarterly, 3, 223-224. http://dx.doi.org/10.1177/153244000300300301

Althaus, S. L., \& Trautman, T. C. (2008). The impact of television market size on voter turnout in American elections. American Politics Research, 36, 824-856. http://dx.doi.org/10.1177/1532673X08317767

Arceneaux, K., Kousser, T., \& Mullin, M. (2012). Get out the vote-by-mail? A randomized field experiment testing the effect of mobilization in traditional and vote-by-mail precincts. Political Research Quarterly, 65, 882-894. http://dx.doi.org/10.1177/1065912911421013

Bowler, S., Donovan, T., \& Happ, T. (1992). Ballot propositions and information costs: Direct democracy and the fatigued voter. The Western Political Quarterly, 45, 559-568. http://dx.doi.org/10.2307/448727 
Brockington, D. (2003). A low information theory of ballot position effect. Political Behavior, 25, 1-27. http://dx.doi.org/10.1023/A:1022946710610

Bullock, C. S., III, \& Dunn, R. E. (1966). Election roll-off: A test of three explanations. Urban Affairs Review, 32, 71-86. http://dx.doi.org/10.1177/107808749603200104

Burnham, W. D. (1965.) The changing shape of the American political universe. The American Political Science Review, 59, 7-28. http://dx.doi.org/10.2307/1976117

Cardy, E. A. (2005). An experimental field study of the GOTV and persuasion effects of partisan direct mail and phone calls. The Annals of the American Academy of Political and Social Science, 601, 8-40. http://dx.doi.org/10.1177/0002716205278051

Carey, J. M., Niemi, R. G., \& Powell, L. (2000). Incumbency and the probability of reelection in state legislative elections. The Journal of Politics, 62, 671-700. http://dx.doi.org/10.1111/0022-3816.00029

CBS News. (n. d.). http://www.cbsnews.com/news/a-record-amount-of-money-spent-on-wisconsin-recall/

Downs, A. (1957). An Economic Theory of Political Action in a Democracy. The Journal of Political Economy, 65, 135-150. http://dx.doi.org/10.1086/257897

Gentzkow, M. (2006). Television and voter turnout. The Quarterly Journal of Economics, 121, 931-972. http://dx.doi.org/10.1162/qjec.121.3.931

Gerber, A. S., \& Green, D. P. (2008). Social pressure and voter turnout: Evidence from a large- scale field experiment. The American Political Science Review, 102, 3-48. http://dx.doi.org/10.1017/s000305540808009x

Gerber, A. S., Green, D. P., \& Green, M. (2003). Partisan mail and voter turnout: Results from randomized field experiments. Electoral Studies, 22, 563-579. http://dx.doi.org/10.1016/S0261-3794(02)00029-X

Green, D. P., \& Gerber, A. S. (2000). The effects of canvassing, telephone calls, and direct mail on voter turnout: A field experiment. The American Political Science Review, 94, 653-663. http://dx.doi.org/10.2307/2585837

Hill, K. Q., \& Leighley, J. E. (1993). Party ideology, organization, and competitiveness as mobilizing forces in gubernatorial elections. American Journal of Political Science, 42, 1158-1178. http://dx.doi.org/10.2307/2111548

Hogan, R. E. (2005). Gubernatorial coattail effects in state legislative elections. Political Research Quarterly, 58, 87-597. http://dx.doi.org/10.1177/106591290505800406

Hogan, R. E. (2013). Campaign spending and voter participation in state legislative elections. Social Science Quarterly, 94, 840-864. http://dx.doi.org/10.1111/j.1540-6237.2012.00897.x

Southwell, P. L. (2009). Analysis of the turnout effects of vote by mail elections, 1980-2007. Social Science Journal, 46, 11-17. http://dx.doi.org/10.1016/j.soscij.2008.12.010

Southwell, P. L., \& Burchett, J. (1997). Survey of vote-by-mail senate election in the state of Oregon. PS: Political Science and Politics, 30, 53-57. http://dx.doi.org/10.1017/S1049096500042633

\section{Copyrights}

Copyright for this article is retained by the author(s), with first publication rights granted to the journal.

This is an open-access article distributed under the terms and conditions of the Creative Commons Attribution license (http://creativecommons.org/licenses/by/3.0/). 